\title{
Trend Analysis of the Value Added Tax in Nepal
}

\author{
Deo Narayan Sutihar*
}

\begin{abstract}
Value added tax (VAT) is the recent one of the sales tax family. This article tries to estimate the share of VAT in Gross Domestic Product (GDP), total tax revenue and indirect tax revenue. Besides, it also estimates the growth rate of VAT. This comprises 2.80 percent and 16.01 percent share of GDP in fiscal year 2000/01 and 2014/15 respectively. It also ranges from 30.69 percent to 37.63 percent share of tax revenue. Likewise, its share ranges from39.94 percent to 50.05 percent. The regression equation has been used to estimate annual growth rate of VAT. The estimate of the annual growth rate of VAT is found to be Rs.6.63billion. From this result, it is obvious that VAT has been increased by Rs. 6.63 billion annually during study period of the fifteen years. The coefficient of determination $\left(\mathrm{R}^{2}\right)$ shows $87.76 \%$ of the total variation in VAT is explained by the variation in time variable. Similarly, the adjusted coefficient of determination ( $\bar{R}^{2}$ ) exhibits that $86.82 \%$ of the total variance in VAT is explained by the variance in time variable. The calculated value of F-distribution is found to be 93.204, which is greater than critical value of $F$ i.e. $F_{0.05}(1,13)=4.67$. It is significant at 5\% level, which exhibits the best fitted regression line. From the statistical analysis, the value of autocorrelation is found to be 0.54 and its $d$-statistic is also found, which is significant at 5 percent level. Thus, the analysis justifies that there is a positive autocorrelation among error terms. To remove the autocorrelation, the transformation data have been used. But, the value of autocorrelation is not found corrected which needs by incorporating other important explanatory variables to further research.
\end{abstract}

Key words: VAT, inland revenue department, time series, trend and growth, autocorrelation, dstatistic

\section{INTRODUCTION}

Value added tax (VAT) is a tax imposed on value added of goods and services by business firms at successive stage of production and distribution. Value added is the excess of sales value over purchased one by a manufacturing or trading firm during a period. A certain percentage of tax is levied on the added value at various levels of such production and distribution. In this sense, a VAT is a multistage sales tax (Subedi, 1998; 79). VAT is the recent one of the sales tax family. In 1919,Dr.WilhelmVol Siemens first proposed the concept of this tax in Germany. The concept of VAT was developed further in 1949 by a mission assigned to purpose of reforms in the tax system of Japan under the chairmanship of Professor Carl Shoup. But no country adopted this tax system until 1954. VAT remained the topic of academic discussion up to this time. After three and half decades of the evaluation of the concept of VAT, France introduced VAT in 1954 as a wholesale

\footnotetext{
${ }^{*}$ Mr. Sutihar is Professor of Economics, PN campus T.U.
} 
level in the industrial sector. In 1959, this tax was confined to the boundary of France. This tax was adopted by Ivory Coast in 1960. After that, Senegal in 1961, Brazil and Denmark followed this tax system in 1967. Thereafter many countries started adopting this tax system.

In Nepal, budget of 1996/97 announced that VAT would be implemented from November 16, 1997 (Mangsir $\left.1^{\text {st }}, 2056\right)$. However, full-fledged VAT was effectively acted from August 17, 1999 (Bhadra $1^{\text {st }}, 2056$ ). Value Added Tax Act has already been enacted in 1996 to regulate actual practice of VAT. According to Value Added Tax Act 1996, the tax rate is 10 percent and exports are subject to a rate of zero percent. There is provision of threshold and exemption in VAT Act 1996. Now the single rate of VAT is 13 percent (IRD, 1996; 36). VAT in Nepal has replaced existing sales tax and other small service based taxes (hotel tax, entertainment tax, contract tax, etc.) have been incorporated. Obviously, the VAT has broadleaved the tax base and increased the revenue elasticity since the FY 1996/97. At the time of introduction, there were only 2,045 taxpayers converted into VAT from the sales tax revenue, but by the end of 2010/11, registration toll has reached to almost 97,664, registering a phenomenon annual growth of 126.42 percent (Koirala, 2011: 65). The total revenue governed from VAT was 2.80 percent of GDP in FY 2000/01 and it is increased to 16.01 percent of GDP in FY 2014/15 (Table 1).

There are many internal sources of VAT collection in Nepal. The major sources of VAT are production, sales and distribution, contract and consultancy, tourism industries and others (IRD, 2069: 47). But, it is generally observed that there are various problems and issues relating to implementation of VAT. VAT billing, fake billing, narrow coverage, weak and traditional tax administration, mass uses of ITC technology in tax administration, lack of coordinated approach and long complex procedure are challenges for proper implementation of VAT in Nepal (Sutihar, 2013: 54).

The main objective of the study is to show the shares of VAT to GDP, total tax revenue and indirect tax revenue. Similarly, it aims to estimate the growth rate of VAT using time series data of 15 years. Likewise, it tries to show existence of autocorrelation among residual terms. The study is very much helpful to all those people who want to get knowledge about the share of VAT to different macro economic variables, estimating equation of linear trend of time series data and existence of autocorrelation among residual terms. However, the findings of the study should be cautiously used because of its limitation only for fifteen years data.

\section{DATA AND METHODS}

This article is based on the secondary data annually published by the Government of Nepal. The Economic Survey Fiscal Year 2007/08 and Fiscal Year 2014/15 of Nepal are the only sources of obtaining statistical data for the present study (Table 01).

The data have been analyzed with the help of different statistical tools such as ratio, percentage, equation of straight line for estimating the annual growth rate of VAT. The standard error of estimate, t-statistic of parameter ' $\mathrm{b}$ ', coefficient of determination $\mathrm{R}^{2}$, adjusted coefficient of determination $\overline{\mathrm{R}}^{2}$, ANOVA table for F-test, coefficient of autocorrelation and Durbin-Watson statistic have also been calculated.

The estimating equation of straight line has been used in the form of $\mathrm{Y}=\mathrm{a}+\mathrm{bX}$, where ' $\mathrm{a}$ ' and ' $\mathrm{b}$ ' are parameters and 'a' stands for the annual average of VAT and 'b' represents annual growth rate of VAT. For these two parameters, the following two normal equations have been used. 
$\sum \mathrm{Y}=\mathrm{na}+\mathrm{b} \sum \mathrm{X}$

$\sum \mathrm{XY}=\mathrm{a} \sum \mathrm{X}+\mathrm{b} \sum \mathrm{X}^{2}$

$\sigma_{y-x}=\sqrt{\frac{\sum e^{2}}{n-2}}$ has been used to find the standard error of estimate, where, $\mathrm{n}$ and $\mathrm{k}$ stand for number of years and parameters respectively.

Table 1: GDP, Total tax, Indirect tax and Value added tax (Rs. in million) and Percentage of VAT in GDP, Total tax revenue and Indirect tax revenue

\begin{tabular}{|llllllrr|}
\hline $\begin{array}{l}\text { Fiscal } \\
\text { Year }\end{array}$ & GDP@ & Total tax & $\begin{array}{l}\text { Indirect } \\
\text { tax }\end{array}$ & VAT & & \multicolumn{3}{c|}{ Percentage of VAT in } \\
\cline { 6 - 8 } & & & & & GDP & Total \\
tax & $\begin{array}{c}\text { Indirect } \\
\text { tax }\end{array}$ \\
\hline $2000 / 01$ & 441519 & 38865.1 & 28705.7 & 12382.4 & 2.80 & 31.86 & 43.14 \\
$2002 / 02$ & 442048 & 39330.6 & 28733.1 & 12267.3 & 2.78 & 31.19 & 42.69 \\
$2003 / 04$ & 459488 & 42587.0 & 32481.2 & 13459.7 & 2.93 & 31.31 & 41.44 \\
$2004 / 05$ & 481004 & 48173.0 & 36260.4 & 14478.9 & 3.01 & 30.69 & 39.94 \\
$2005 / 06$ & 514460 & 57430.4 & 43462.3 & 21610.7 & 4.20 & 37.63 & 49.73 \\
$2006 / 07$ & 532038 & 71127.0 & 52147.0 & 26095.6 & 4.90 & 36.69 & 50.05 \\
$2007 / 08$ & 564517 & 85155.5 & 62075.5 & 29815.7 & 5.28 & 35.01 & 48.03 \\
$2008 / 09$ & 590107 & 117052.9 & 82731.2 & 39700.9 & 6.73 & 33.92 & 47.98 \\
$2009 / 10$ & 618529 & 156294.9 & 114544.9 & 54920.9 & 8.88 & 35.14 & 47.94 \\
$2010 / 11$ & 639694 & 177227.2 & 130506.9 & 61663.6 & 9.64 & 34.79 & 47.25 \\
$2011 / 12$ & 670279 & 211721.8 & 153951.6 & 70930.4 & 10.58 & 33.50 & 46.07 \\
$2012 / 13$ & 697954 & 259214.9 & 186202.3 & 83418.4 & 11.95 & 32.18 & 44.80 \\
$2013 / 14$ & 735508 & 312411.3 & 225698.9 & 101104.6 & 13.75 & 32.26 & 44.80 \\
$2014 / 15^{*}$ & 760243 & 371706.0 & 272697.5 & 121730.7 & 16.01 & 32.75 & 44.64 \\
\hline
\end{tabular}

(a) GDP at constant price.*Estimated.

Sources: Economic Survey, Fiscal Year 2007/08, Table 1.2; 2, Table 2.2; 14.

Economic Survey, Fiscal Year 2014/15, Table 1.2;2, Table 2.2; 14.

The statistical hypothesis for parameter ' $b$ ' has been set up and tested. The t-statistic has been used to test the significance of the parameter.

The null and alternative hypotheses for the parameter ' $b$ ' have been used for the significance of annual growth rate of VAT.

Null hypothesis $\mathrm{H}_{0}: \mathrm{b}=0$, i.e. annual growth rate of VAT is not significant at $5 \%$ level of significance with $\mathrm{n}-2$ degrees of freedom.

Alternative hypothesis $\mathrm{H}_{1}$ : b $>0$, i.e. annual growth rate of VAT is significant at $5 \%$ level of significance with $\mathrm{n}-2$ degrees of freedom.

Test statistic: Under null hypothesis $\left(\mathrm{H}_{\mathrm{o}}\right)$, the test statistic is: $t_{(b)}=\frac{b}{\operatorname{Se}(b)}$

Coefficient of determination $\mathrm{R}^{2}$ and adjusted coefficient of determination $\overline{\mathrm{R}}^{2}$ have also been computed by using the following method: 


$$
R^{2}=1-\frac{\sum e^{2}}{\sum y^{2}} \text { and } \bar{R}^{2}=1-\frac{\sum e^{2}}{\sum y^{2}} \times \frac{n-1}{n-k} .
$$

Hypotheses for Regression line

Null hypothesis $\mathrm{H}_{0}: \mathrm{b}=0$, the regression line of $\mathrm{Y}$ on $\mathrm{X}$ is not significant at $5 \%$ level of significance with $\mathrm{k}-1, \mathrm{n}-2$ degrees of freedom.

Alternative hypothesis $\mathrm{H}_{1}: \mathrm{b}>0$, the regression line of $\mathrm{Y}$ on $\mathrm{X}$ is significant at $5 \%$ level of significance with 1,13 degrees of freedom.

Test statistic: Under null hypothesis $\left(\mathrm{H}_{\mathrm{o}}\right)$, the test statistic is: $F=\frac{M S R}{M S E}$

Where, MSR = Mean of explained variation and MSE= Mean of unexplained variation.

Similarly, the first order autocorrelation among residual terms has been calculated by using the

formula: $\rho=\frac{\sum_{i=2}^{t} e_{t} e_{t-1}}{\sum_{i=1}^{t} e_{t}^{2}}$ and the D-W statistic has been used to test the following hypothesis:

Null hypothesis $H_{0}: \rho=0$, i.e. there is no presence of positive autocorrelation among residual terms.

Alternative hypothesis $H_{1}: \rho>0$, i.e. there is presence of positive autocorrelation among residual terms.

Test statistic: Under null hypothesis $\left(\mathrm{H}_{\mathrm{O}}\right): \sum_{d=\frac{\sum_{i=2}^{t}\left(e_{t}-e_{t-1}\right)^{2}}{\sum_{i=1}^{t} e_{t}^{2}}}$.

This statistic measures the correlation between each residual and the residual for the time period immediately preceding one.

\section{RESULTS AND INTERPRETATION}

The present study evaluates the VAT to GDP ratio, which ranges from 2.8 percent in FY 2000/01 to 16.01 percent in FY 2014/15. This ratio has been increasing from FY 2000/01 to FY 2014/15. Similarly, VAT to total tax ratio fluctuates from 30.69 percent to 37.63 percent. Likewise, VAT to indirect tax ratio oscillates from 39.94 percent to 50.05 percent during the study period (Table 01 ). This study also estimates the average value and growing rate of value added tax during 15 years. It has been estimated through the analysis of time series data for 15 years from FY 2000/01 to FY $2014 / 15$. It is obvious that the annual growing rate of value added tax has been estimated to be Rs. 6.63 billion during the study period. This exhibits that VAT is increasing by Rs. 6.63 billion per year (Annex 1).The increasing trend of VAT exhibits that revenue from VAT to government revenue of Nepal is increasing continuously during the study period (Figure 1).

The standard error of estimate has been estimated Rs. 12.82 billion. Likewise, the standard error of parameter ' $b$ ' at an annual growing rate is Rs. 2.42 billion.

The calculated value of $t_{(b)}$ is 2.738 . It is greater than the critical value of $t_{0.05}(13)=2.160$ (Two tailed test), which comprises that null hypothesis is rejected and alternative hypothesis is accepted at $5 \%$ level. Therefore, it is concluded that annual growth rate of VAT is significant.The coefficient of determination is 0.8776 . It shows that $87.76 \%$ of the total variation in VAT is explained by the variation in time variable. Similarly, the adjusted coefficient of determination is 
0.8682 , which exhibits that $86.82 \%$ of the total variance in VAT is explained by the variance in time variable.

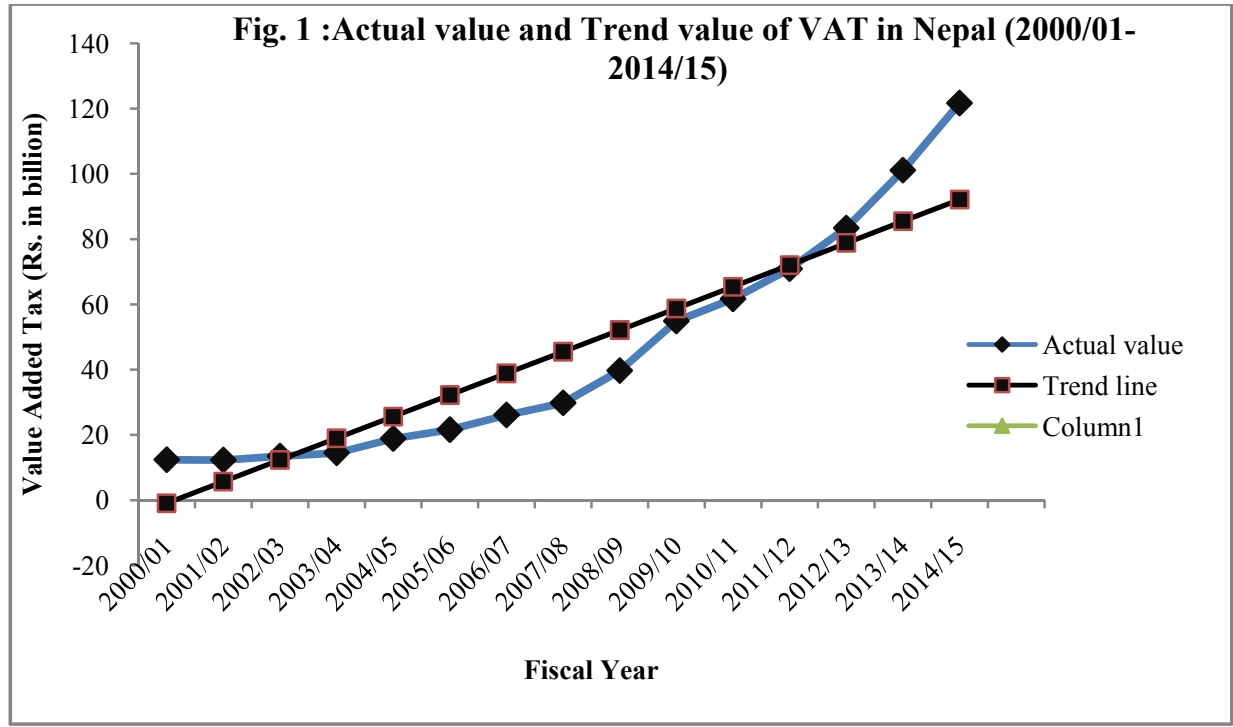

The calculated value of F-distribution is found to be 93.204, which is greater than critical value of $\mathrm{F}$ i.e. $\mathrm{F}_{0.05}(1,13)=4.67$. It is significant at $5 \%$ level. Hence, null hypothesis is rejected and alternative hypothesis is accepted. From this result, it is concluded that the regression line of $\mathrm{Y}$ on $\mathrm{X}$ is best fitted (Annex 02).

The coefficient of autocorrelation $(\rho)$ is found to be 0.54 and its d-statistic has been estimated as 0.271 . This value is less than $d_{L}=1.077$ at $5 \%$ level of significance with $\mathrm{k}^{\prime}=1$ and $\mathrm{n}=15$. Therefore, it is concluded that there is presence of positive autocorrelation among residual terms in the study period. The transformed data of VAT and time variables have been used to remove the presence of autocorrelation. After estimating new equation of straight line trend of VAT is $\hat{Y}^{\prime}=-17.05+9.73 X^{\prime}$. The coefficient of autocorrelation $\left(\rho^{\prime}\right)$ has been found to be 0.52 and its d-statistic has been estimated as 0.524 . This value is less than $d_{L}=1.045$ at $5 \%$ level of significance with $\mathrm{k}^{\prime}=1$ and $\mathrm{n}=14$. Therefore, it is concluded that there is again the presence of positive autocorrelation among residual terms which needs to further research by incorporating other important explanatory variables.

\section{CONCLUSION}

From the analysis of data, it is obvious that the share of VAT/GDP ratio has been fluctuated from 2.8 percent to 16.01 percent during the study period. Similarly, the share of VAT/total tax ratio has been found to vary from 30.69 percent to 37.63 percent in the same period. Likewise, the share of VAT/indirect tax ratio has been found to vary from 39.94 percent to 50.05 percent in the study period. The annual growth rate of VAT is also found to be reached Rs. 6.63 billion in same period. This annual growing trend of VAT exhibits that the Government of Nepal would be able to receive a large amount of revenue from VAT in near future. 
The coefficient of determination $\left(\mathrm{R}^{2}\right)$ is 0.8776 . It shows that $87.76 \%$ of the total variation in VAT is explained by the variation in time variable. Similarly, the adjusted coefficient of determination $\left(\bar{R}^{2}\right)$ is 0.8682 , which exhibits that $86.82 \%$ of the total variance in VAT is explained by the variance in time variable.

The calculated value of F-distribution is found to be 93.204 which is greater than critical value of F i.e. $F_{0.05}(1,13)=4.67$. It is significant at $5 \%$ level of significance with 1,13 degrees of freedom. It is concluded that the estimated regression line of VAT is best fitted to the time series data.

The value of autocorrelation is found to be 0.54 and its d-statistic has been estimated 0.271 , which exhibits that there is positive autocorrelation among residual terms. Similarly, after the transformed data, the value of autocorrelation is found to be 0.52 and its d-statistic is estimated 0.524 , which exhibits that there is again positive autocorrelation among residual terms.

\section{REFERENCES}

Inland Revenue Department (2069). Annual report 2067/68, Kathmandu: Ministry of Finance, Government of Nepal.

--------(1995). Value added tax Act 1995, Kathmandu: Ministry of Finance, Government of Nepal.

Khadka, R. (2001). Value added tax: The concept, international experiences and its application in Nepal, Value Added Tax Four Years of Implementation. In R. Khadka, ed., Inland Revenue Department and Value Added Tax Project, 91-146.

Koirala, K. (2011). Value added tax (VAT) in Nepal: A critical assessment of its performance. The Journal of Nepalese Business Studies, VII (I); 63-69.

Ministry of Finance (2008). Economic Survey, Fiscal Year 2007/08, Kathmandu: Government of Nepal.

(2015). Economic Survey, Fiscal Year 2014/15, Kathmandu: Government of Nepal.

Subedi, B.R. (1998). VAT and its applicability in Nepal, Kathmandu: Bhrikuti Prakashan.

Sutihar, D.N. (2010). Quantitative Techniques, Kathmandu: Pairavi Prakashan. -(2013). Contribution of value added tax in Nepal. The Journal of Nepalese Business Studies, VIII (I); 53-59. 


\section{ANNEXES}

Annex 1:Value added tax (Rs. in billion) and calculation of sum and square values

\begin{tabular}{|c|c|c|c|c|c|c|c|c|c|c|}
\hline Year & $\begin{array}{l}\text { VAT } \\
(\mathrm{Y})\end{array}$ & $\begin{array}{l}\text { Tim } \\
\text { e } \\
(\mathrm{X})\end{array}$ & $\mathrm{X}^{2}$ & $\mathrm{XY}$ & $\hat{\mathrm{Y}}$ & $e_{t}$ & $\mathrm{X}^{\prime}$ & $\mathrm{Y}^{\prime}$ & $\hat{Y}^{\prime}$ & $e_{t}{ }^{\prime}$ \\
\hline $2000 / 01$ & 12.4 & 1 & 1 & 12.4 & -0.91 & 13.3 & - & - & - & - \\
\hline $2001 / 02$ & 12.3 & 2 & 4 & 24.6 & 5.72 & 6.58 & 1.46 & 5.60 & -2.84 & 8.44 \\
\hline $2002 / 03$ & 13.5 & 3 & 9 & 40.5 & 12.35 & 1.15 & 1.92 & 6.86 & 1.63 & 5.23 \\
\hline $2003 / 04$ & 14.5 & 4 & 16 & 58.0 & 18.18 & -4.48 & 2.38 & 7.21 & 6.11 & 1.10 \\
\hline $2004 / 05$ & 18.9 & 5 & 25 & 94.5 & 25.61 & -6.71 & 2.84 & 11.07 & 10.58 & 0.49 \\
\hline $2005 / 06$ & 21.6 & 6 & 36 & 129.6 & 32.24 & -10.64 & 3.30 & 11.39 & 15.06 & -3.67 \\
\hline $2006 / 07$ & 26.1 & 7 & 49 & 182.7 & 38.87 & -12.77 & 3.76 & 14.44 & 19.53 & -5.09 \\
\hline $2007 / 08$ & 29.8 & 8 & 64 & 238.4 & 45.50 & -15.70 & 4.22 & 15.71 & 24.06 & -8.30 \\
\hline $2008 / 09$ & 39.7 & 9 & 81 & 357.3 & 52.13 & -12.43 & 4.68 & 23.61 & 28.49 & -4.88 \\
\hline $2009 / 10$ & 54.9 & 10 & 100 & 549.0 & 58.76 & -3.86 & 5.14 & 33.46 & 32.96 & 0.50 \\
\hline $2010 / 11$ & 61.7 & 11 & 121 & 678.7 & 65.39 & -3.69 & 5.60 & 32.05 & 37.44 & -5.39 \\
\hline $2011 / 12$ & 70.9 & 12 & 144 & 850.8 & 72.02 & -1.12 & 6.06 & 37.58 & 41.91 & -3.81 \\
\hline $2012 / 13$ & 83.4 & 13 & 169 & $1084 / 2$ & 78.85 & 4.75 & 6.52 & 45.11 & 46.39 & -1.28 \\
\hline $2013 / 14$ & 101.1 & 14 & 196 & 1415.4 & 85.48 & 15.62 & 6.98 & 56.06 & 50.87 & 5.19 \\
\hline $2014 / 15$ & 121.7 & 15 & 225 & 1825.5 & 92.11 & 29.59 & 7.44 & 67.11 & 55.34 & 11.77 \\
\hline & $\begin{array}{l}\sum_{=682.5} Y \\
=\end{array}$ & $\underset{=120}{\sum X}$ & $\underset{=1240}{\sum X^{2}}$ & $\underset{=7541.6}{\sum X Y}$ & $\begin{array}{l}\sum \hat{\mathrm{Y}} \\
=682.5\end{array}$ & & $\sum_{=62.3} X^{\prime}$ & $\sum_{=367.26} Y^{\prime}$ & $\sum_{=367.26} \hat{Y}^{\prime}$ & \\
\hline
\end{tabular}

Source: Adapted and calculated from Table 1.

Regression equation of VAT (Y) on time (X): $\mathrm{Y}=\mathrm{a}+\mathrm{bX}$

For the parameters ' $a$ ' and 'b', following two normal equations have been solved.

$\sum \mathrm{Y}=\mathrm{na}+\mathrm{b} \sum \mathrm{X}$ and $\sum \mathrm{Y}=\mathrm{a} \sum \mathrm{X}+\mathrm{b} \sum \mathrm{X}^{2}$

After substituting the values

$682.5=15 \mathrm{a}+120 \mathrm{~b}$ and $7541.6=120 \mathrm{a}+1240 \mathrm{~b}$

After solving these two equations, the values of ' $a$ ' and ' $b$ ' have been obtained and the estimated regression equation is $\hat{Y}=-7.54+6.63 X$

$\sigma_{y . . x}=\sqrt{\frac{\sum e^{2}}{n-2}}=12.8176 \operatorname{Se}(b)=\sqrt{\frac{\sum e^{2}}{n-2}\left[\frac{1}{\sum x^{2}}\right]}=2.4223$

Where, $\sum \mathrm{x}^{2}=\sum \mathrm{X}^{2}-\left(\frac{\sum \mathrm{X}}{\mathrm{n}}\right)^{2}=280, \sum \mathrm{y}^{2}=\sum \mathrm{Y}^{2}-\left(\frac{\sum \mathrm{Y}}{\mathrm{n}}\right)^{2}=17448.28$

$\sum e_{t}{ }^{2}=\sum(Y-\hat{Y})^{2}=2135.77, \sum e_{t} e_{t-1}=1147.9$ and $\sum\left(e_{t}-e_{t-1}\right)^{2}=578.7$

Test statistic: Under null hypothesis $\left(\mathrm{H}_{\mathrm{o}}\right)$, the test statistic is: $t_{(b)}=\frac{b}{\operatorname{Se}(b)}=\frac{6.63}{2.42}=2.7397$

Coefficient of determination: $\mathrm{R}^{2}=1-\frac{\sum \mathrm{e}^{2}}{\sum \mathrm{y}^{2}}=0.8776$ 
Adjusted coefficient of determination: $\overline{\mathrm{R}}^{2}=1-\frac{\sum \mathrm{e}^{2} / \mathrm{n}-2}{\sum \mathrm{y}^{2} / \mathrm{n}-1}=0.8682$

Annex 2: ANOVA Table

\begin{tabular}{|l|l|l|l|l|}
\hline $\begin{array}{l}\text { Source of } \\
\text { variation }\end{array}$ & $\begin{array}{l}\text { Sum of squares } \\
(\mathrm{SS})\end{array}$ & $\begin{array}{l}\text { Degrees of } \\
\text { freedom }(\mathrm{df})\end{array}$ & $\begin{array}{l}\text { Mean sum of } \\
\text { squares (MS) }\end{array}$ & F-ratio \\
\hline $\begin{array}{l}\text { Due to } \\
\text { regression }\end{array}$ & $\mathrm{SSR}=15322.51$ & $\mathrm{k}-1=1$ & $\begin{array}{l}\text { MSR }=\frac{S S R}{k-1} \\
=15312.51 \\
\text { MSE }=\frac{S S E}{n-k}\end{array}$ & $F=\frac{M S R}{M S E}$ \\
$\begin{array}{l}\text { Due to residual } \\
\text { Total }\end{array}$ & $\mathrm{SSE}=2135.77$ & $\mathrm{n}-\mathrm{k}=13$ & $=164.29$ & $=93.204$ \\
\hline
\end{tabular}

$\sum \mathrm{y}^{2}=$ Total variation ( $\mathrm{SST}=$ Total sum of squares), $\sum \mathrm{e}^{2}=$ Unexplained variation ( $\mathrm{SSE}=\mathrm{Sum}$ of residual squares) and $\sum \mathrm{y}^{2}-\sum \mathrm{e}^{2}=$ Explained variation ( $\mathrm{SSR}=\mathrm{Sum}$ of regression squares)

$\rho=\frac{\sum_{i=2}^{t} e_{t} e_{t-1}}{\sum_{i=1}^{t} e_{t}{ }^{2}}=\frac{1147.9}{2135.77}=0.54, d=\frac{\sum_{i=2}^{t}\left(e_{t}-e_{t-1}\right)^{2}}{\sum_{i=1}^{t} e_{t}{ }^{2}}=\frac{578.7}{2135.77}=0.271$

Regression equation of transformed value $\left(Y^{\prime}\right)$ on time $\left(X^{\prime}\right): Y^{\prime}=a^{\prime}+b^{\prime} X^{\prime}$, where,

$$
X_{n}^{\prime}=X_{n}-\rho X_{n-1} \text { and } Y_{n}^{\prime}=Y_{n}-\rho Y_{n-1}
$$

For the parameters $a^{\prime}$ and $b^{\prime}$, following two normal equations have been solved.

$$
\sum Y^{\prime}=n a^{\prime}+b^{\prime} \sum X^{\prime} \text { and } \sum Y^{\prime}=a^{\prime} \sum X^{\prime}+b^{\prime} \sum X^{\prime 2}
$$

After substituting the values

$$
682.5=15 a^{\prime}+120 b^{\prime} \text { and } 7541.6=120 a^{\prime}+1240 b^{\prime}
$$

After solving these two equations, the values of ' $a$ ' and ' $b$ ' have been obtained and the estimated regression equation is $\hat{Y}^{\prime}=-17.05+9.73 X^{\prime}$

$$
\rho^{\prime}=\frac{\sum_{i=3}^{t} e_{t}^{\prime} e_{t-1}^{\prime}}{\sum_{i=2}^{t} e_{t}^{{ }^{2}}}=\frac{1147.9}{433.04}=0.52 \text { and } d^{\prime}=\frac{\sum_{i=3}^{t}\left(e^{\prime}{ }_{t}-e^{\prime}{ }_{t-1}\right)^{2}}{\sum_{i=2}^{t} e^{\prime}{ }_{t}{ }^{2}}=\frac{266.75}{433.04}=0.524
$$

